\title{
Factors that may influence the score in the College Admission Test in China
}

Ma Ling ${ }^{1}$, Yang Yue ${ }^{1}$, Lou Ning ${ }^{2}$

${ }^{1}$ Department of Anesthesiology, Shengjing Hospital of China Medical University,
Shengjing, China

${ }^{2}$ Department of Anesthesiology, Central Hospital of Cangzhou, Cangzhou, China

Submitted: 7 February 2017

Accepted: 9 March 2017

Arch Med Sci Civil Dis 2016; 1: e50-e54

DOI: https://doi.org/10.5114/amscd.2017.66704

Copyright @ 2016 Termedia \& Banach

\section{Abstract}

Introduction: Many factors may influence the score of the College Admission Test. The purpose of this study was to assess the factors that may predict students' scores in the College Admission Test in China.

Material and methods: We sent out 1000 questionnaires which consisted of the following items: objective data on demographic factors, their scores of the test, the year they attended the test, whether they took a set of "art" subjects or a set of "science" subjects, the monthly salary of the whole family, the highest academic degree obtained by the father and mother, the history of past operations and the name and the times of operations undergone, as well as the type of anesthesia received by those who took the College Admission Test.

Results: Univariate analyses showed that age, gender, household income, parental education, and anesthesia history may influence College Admission Test scores. These variables were subsequently entered into the multivariate linear regression model. Students with a history of local anesthesia are predicted to have a score 8.1 points lower than the average $(-8.1,95 \% \mathrm{Cl}$ : $-15,-1)$ and this effect is statistically significant $(p=0.025)$. Students with a history of general anesthesia are also predicted to have lower scores $(-2.8$, $95 \% \mathrm{Cl}:-16,10.2)$ than the average, but the difference is not statistically significant.

Conclusions: The present findings suggest that the scores in the College Admission Test may be associated with age, gender, father's education and the use of local anesthetics. Ever receiving local anesthesia had a negative impact on College Admission Test scores.

Key words: general anesthesia, local anesthesia, College Admission Test, questionnaire.

\section{Introduction}

Because of the complexity of the mechanisms of general anesthesia and its potential effects on various organs, more and more attention has been drawn to the effects of general anesthesia on the brain development.

A growing number of animal experiments has shown that the clinically commonly used anesthetics have neurotoxic effects on brain development, and can cause long-term neurobehavioral abnormalities. At the same time, clinical studies on the relation between pediatric anesthesia and its subsequent learning and behavior disorders remain controversial $[1,2]$.

\author{
Corresponding author: \\ Ma Ling \\ Department of \\ Anesthesiology \\ Shengjing Hospital of \\ China Medical University \\ No. 36 Sanhao Street \\ Heping District \\ Shenyang, 110004, China \\ Phone: +86 18940256927 \\ E-mail: maling27@hotmail.com
}


Experiments with 14 days of pregnant mice exposed to $2.5 \%$ concentration of sevoflurane for $2 \mathrm{~h}$ showed the activation of cysteine protease and increased caspase-3 and interleukin-6 (IL-6) levels in newborn mice. The sevoflurane anesthesia impaired learning and memory in the 31-dayold offspring mice [3]. This may be related to the increase of intracellular $\mathrm{Ca}^{2+}$ ion concentration,

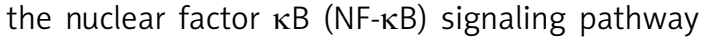
activation and significantly increased levels of proinflammatory cytokines.

Utskits [4] found that a clinically relevant concentration of propofol could cause dendritic axis change for a long time in immature rats' neurons. After continuous exposure to propofol for $4 \mathrm{~h}$, the dendritic growth rate dropped significantly. Another in vitro study found that propofol can induce long-term depression in the hippocampal CA1 region of adult rats [5].

Animal experiments have shown considerable achievements, confirming that general anesthesia can induce neuronal apoptosis, influence the formation of synapses, and change the neurotransmitter number. However, some studies showed no impacts of anesthesia and some even drew the opposite conclusions that instead of adversely impacting brain development, general anesthetics will even protect brain function and improve learning ability and memory [6].

Clinical experiments studying the effects of general anesthetics on children's memory have been performed. Pham et al. [7] studied 5- to 12-year-old children who accepted general anesthesia, and found that general anesthesia did not interfere in the process of memory formation. Yin et al. [8] compared the effect of propofol and sevoflurane in 7-to 13-year-old children on the short-term and long-term memory, and found that propofol affected the short-term memory, but neither anesthetic affected the long-term memory.

In this study we want to evaluate the impact of anesthetics on brain function by studying factors that may influence the College Admission Test scores. The College Admission Test is an academic examination held annually in China. This examination is a prerequisite for entrance into almost all higher education institutions at the undergraduate level. The overall mark received by the student is generally a weighted sum of their subject marks. Many factors may influence the score of the examination: age, gender, economic level of the family and educational level of the parents. In this study, we are particularly interested in whether anesthesia (either general anesthesia or local anesthesia) received during childhood may affect the child's intelligence. This relationship has never been evaluated before.

\section{Material and methods}

We sent out questionnaires to 1000 students. The questionnaire contained the following items: objective data on demographic factors (gender, the age at which they attended the College Admission Test, the province in which they attended), their scores in the test, the year they attended the test, whether they took a set of "art" subjects or a set of "science" subjects, the monthly salary of the whole family, the highest academic degree obtained by father, the highest academic degree obtained by mother, whether they had a history of past operations and, if yes, the name and the times of operations undergone, as well as the type of anesthesia (local anesthesia or general anesthesia) received.

\section{Statistical analysis}

Means and standard deviations were used to describe the distribution of continuous variables. Percentages were used to describe the distribution of categorical variables. We used linear regression to evaluate factors that may influence the College Admission Test scores. We first used a univariate analysis to assess the association of each variable: age, gender, household income, father's education, mother's education, an indicator variable for surgery history, an indicator variable for anesthesia history, local anesthesia and global anesthesia. The variables that may be associated with College Admission Test scores were entered in the final linear regression model. SPSS17.0 (Chicago, IL, USA) was used for all statistical analyses.

\section{Results}

We received 568 responses out of the 1000 questionnaires sent out. Considering the fact that the College Admission Test score distribution varies across different provinces and different years, we focused our analysis on the 344 subjects who attended the College Admission Test in Liaoning Province in 2013 (Figure 1). We further removed 2 subjects with scores being outliers, 3 subjects with missing information on the College Admission Test score and 8 subjects with missing information on surgery history. Of the 331 subjects in the final analysis, 38 subjects had a history of surgical anesthesia, 9 with general anesthesia history, 29 with local anesthesia history and 6 with missing information on anesthesia subtypes (Figure 1).

Characteristics of the samples are listed in Table I. Of the 344 students, those who had no anesthesia history had a mean College Admission Test score of $585.4 \pm 20.7$ (mean \pm SD), while the mean scores for those with a history of general anesthesia or local anesthesia are $582.9 \pm 11.5$ and $574.4 \pm 19.7$, respectively. The score distribution 


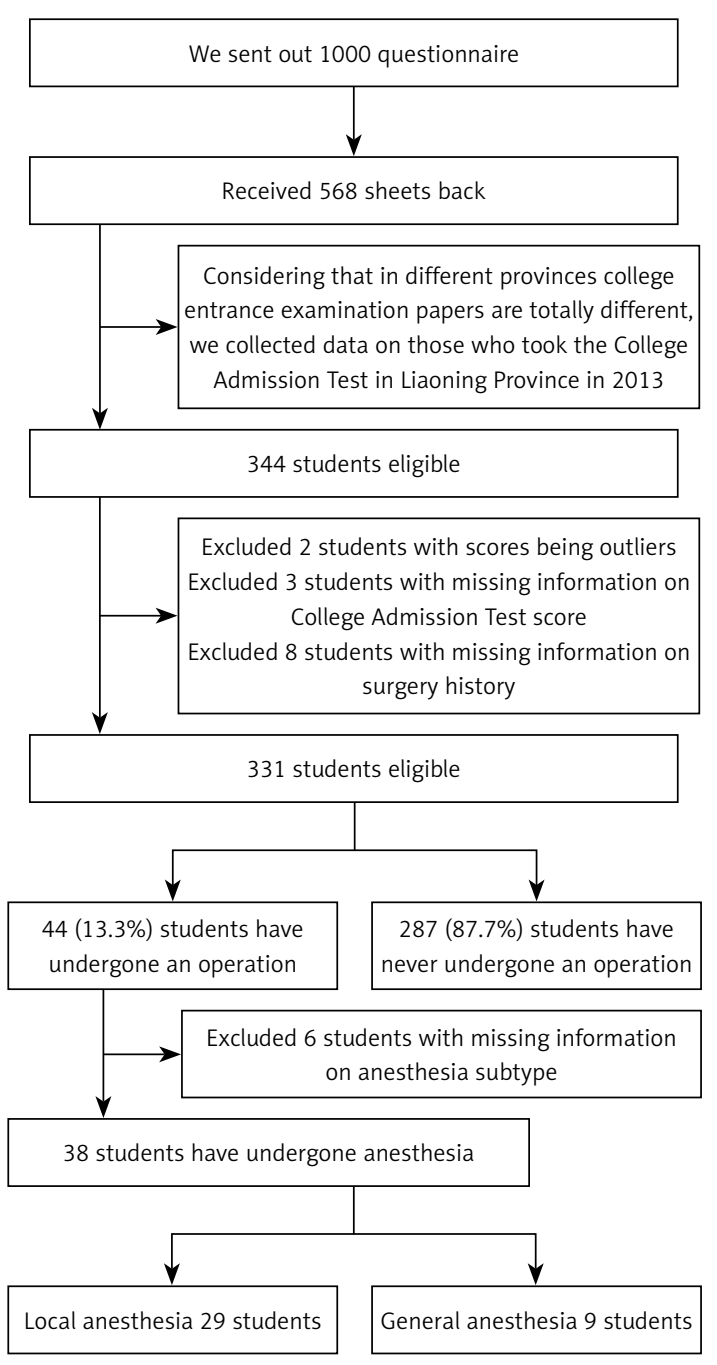

Figure 1. Flowchart of sample collection

among the three groups is also shown in Figure 2 . As shown in both Table I and Figure 2, those with a history of local anesthesia tend to have a slightly lower score. The ages of the students in the three groups are comparable: $18.8 \pm 0.85,19.2$ \pm 1.39 and $18.6 \pm 0.69$. We categorized household income into 5 groups (<2000 Yuan, 2000-5000 Yuan, 5000-10,000 Yuan, 10,000-20,000 Yuan and $>20,000$ Yuan) and the parents' education into 5 groups (elementary, middle school, high school, undergraduate and graduate school). The distributions of these variables are shown in Table I.

Univariate analyses showed that age, gender, household income, parental education, and anesthesia history may influence College Admission Test scores. These variables were subsequently entered in the multivariate linear regression model. Due to the high correlation between the parental education statuses, the mother's education has no effects after adjusting for the father's education. Mother's education was therefore removed from the final model. The multivariate linear regression results showed that age, gender, father's education and the use of local anesthetics were associated with score. The score is predicted to increase by 7.6 with a one-year increment in age. Females tend to have a higher score than males. Students from families in the higher household income categories tend to have higher scores. Students with a history of local anesthesia are predicted to have a score 8.1 points lower than the average $(-8.1,95 \% \mathrm{Cl}:-15,-1)$, and this effect is statistically significant $(p=0.025)$. Students with a history of general anesthesia are also predicted to have lower scores $(-2.8,95 \% \mathrm{Cl}:-16,10.2)$ than the average, but the difference is not statistically significant. We further evaluated the potential effects of the frequency of anesthetic usage and age at last anesthetic usage on the score among individuals with a history of anesthetic usage. Neither the frequency of usage or age at last usage impacted the score significantly.

\section{Discussion}

The present findings suggest that the scores in the College Admission Test may be associated with age, gender, father's education and the use of local anesthetics.

Taqhon et al. [9] reported that early anesthetic exposure and surgery did not affect accurate response time or activation patterns in the primary region of interest during performance of the task. Our univariate analysis showed a non-significant negative correlation between age and the score. Our student's ages were very close, ranging from 17 to 20 years when they took the College Admission Test, which probably explained the non-significant difference in their scores.

We identified a negative association between a history of local anesthesia and College Admission Test scores. Those who received local anesthesia had relatively low scores. This may be related to the stress caused by local anesthetics in the teenagers. The failure to observe an association with general anesthesia may be due to the limited sample size.

At present, there are vast studies about the effect of the anesthetic on the immune neurons or synaptic structure. For the developing brain, especially in the synapse formation period, the high chloride ion concentration in the cell and the activation of GABA receptor can cause the outflow of chloride ions, depolarization, and the increase of $\mathrm{Ca}^{2+}$ levels inside the cell, which can cause damage to cells [10].

Backeljauw et al. [11] reported that general anesthesia for a surgical procedure in early childhood may be associated with long-term diminution of language abilities and cognition, as well as regional volumetric alterations in brain structure. 
Table I. Characteristics of the study participants

\begin{tabular}{|c|c|c|c|c|}
\hline \multicolumn{2}{|l|}{ Parameter } & $\begin{array}{l}\text { No anesthesia } \\
\text { history }\end{array}$ & General anesthesia & Local anesthesia \\
\hline \multicolumn{2}{|l|}{$N(\%)$} & $287(88.3)$ & $9(2.8)$ & $29(8.9)$ \\
\hline \multirow{2}{*}{$\begin{array}{l}\text { College Admission } \\
\text { Test Scores }\end{array}$} & Mean (SD) & $585.4(20.7)$ & $582.9(11.5)$ & $574.4(19.7)$ \\
\hline & $N(\%)$ & $287(88.3)$ & $9(2.8)$ & $29(8.9)$ \\
\hline \multicolumn{2}{|c|}{ Age [years] mean (SD) } & $18.8(0.85)$ & $19.2(1.39)$ & $18.6(0.69)$ \\
\hline \multirow[t]{3}{*}{ Gender } & Male & 176 & 8 & 24 \\
\hline & Female & 110 & 1 & 5 \\
\hline & Missing & 1 & 0 & 0 \\
\hline \multirow{6}{*}{$\begin{array}{l}\text { Household } \\
\text { income per } \\
\text { month }\end{array}$} & $<2000$ Yuan & 71 & 4 & 16 \\
\hline & 2000-5000 Yuan & 119 & 2 & 8 \\
\hline & 5000-10,000 Yuan & 70 & 1 & 4 \\
\hline & 10,000-20,000 Yuan & 7 & 1 & 1 \\
\hline & $>20,000$ Yuan & 8 & 0 & 0 \\
\hline & Missing & 12 & 1 & 0 \\
\hline \multirow{6}{*}{$\begin{array}{l}\text { Father's } \\
\text { education }\end{array}$} & Elementary & 38 & 2 & 8 \\
\hline & Middle school & 86 & 1 & 13 \\
\hline & High school & 83 & 3 & 5 \\
\hline & Bachelor's degree & 69 & 3 & 3 \\
\hline & Master's degree and above & 7 & 0 & 0 \\
\hline & Missing & 4 & 0 & 0 \\
\hline \multirow{6}{*}{$\begin{array}{l}\text { Mother's } \\
\text { education }\end{array}$} & Elementary & 39 & 3 & 8 \\
\hline & Middle school & 87 & 2 & 11 \\
\hline & High school & 83 & 1 & 5 \\
\hline & Bachelor's degree & 66 & 3 & 5 \\
\hline & Master's degree and above & 9 & 0 & 0 \\
\hline & Missing & 3 & 0 & 0 \\
\hline
\end{tabular}

Clinical research evidence on neurotoxicity produced by the general anesthetics in infants and young children is insufficient. Two large-scale retrospective clinical studies proved that exposure to the anesthetic experience is related to children's later failing grades and abnormal behavior. One analyzed the questionnaire filled by parents [12]. Neurobehavioral development was assessed using the validated 120 -item parental Child Behavior Check List /4-18 in 314 children who were operated on for pediatric urological procedures between the ages of 0 and 6 years old. The results showed that having surgery under general anesthesia before the age of 1 to 2 years old was associated with the possibility of abnormal behavior in children. These findings were, however, not statistically significant, as indicated by the wide confidence intervals.

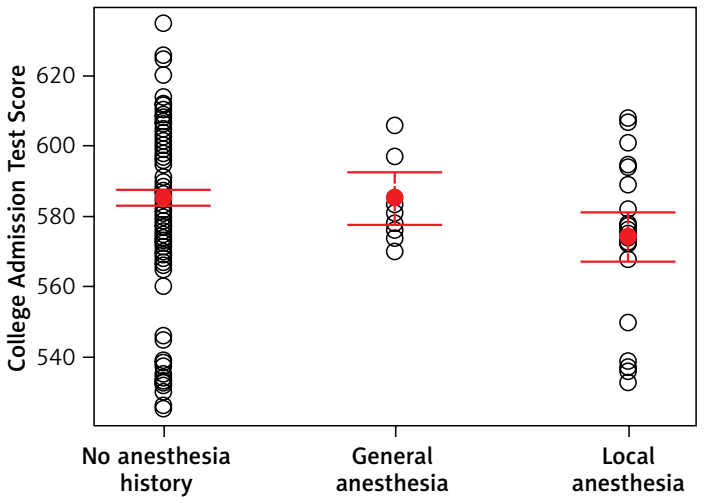

Figure 2. Distribution of College Admission Test scores among the three groups of anesthesia history: no anesthesia history, history of local anesthesia and history of general anesthesia. Each circle represents a score from a participant. The red dots show the mean and the red lines denote the upper and lower limits of the $95 \%$ confidence interval 
A second study [13], which compared children who had general anesthesia before the age of 4 with those did not receive general anesthesia, found no significant difference in learning ability. However, the children who received general anesthesia twice or more times had declined learning abilities, and the longer the duration of anesthesia was, the greater was the risk of learning disabilities.

In conclusion, the scores in the College Admission Test may be associated with age, gender, father's education and the use of local anesthetics. Further pharmacological studies are needed to prove the speculation. Although causation remains unresolved, these findings warrant additional research into the phenomenon's mechanism and mitigating strategies.

Our study has some limitations. The sample size in this survey was relatively small and the data collected by the questionnaires may not represent all the factors that influence the College Admission Test scores. Our estimates have wide confidence intervals due to the limited sample size. We only included college students in our study, and the College Admission Test scores collected did not have a wide distribution. We do not have scores in the lower score range in our study. The maximum score of the College Admission Test is 750 . The scores in our study ranged from 525 to 700 , with an average of 571.8 , which is relative high considering the score distribution of the entire student group. The ages of our study participants were very close, ranging from 17 to 20 years when they took the College Admission Test, which probably explains the non-significant difference in their scores. We used a retrospective study design in this study, where recall bias is always a concern. A prospective study may draw a more persuasive conclusion.

\section{Acknowledgments}

We wish to thank all the participants for their cooperation in the data collection.

Source of funding: National Natural Science Foundation of China (No. 81302534).

\section{Conflict of interest}

The authors declare no conflict of interest.

\section{References}

1. Ing $\mathrm{CH}$, DiMaggio CJ, Malacova E, et al. Comparative analysis of outcome measures used in examining neurodevelopmental effects of early childhood anesthesia exposure. Anesthesiology 2014; 120: 1319-32.

2. Hansen TG. Anesthesia-related neurotoxicity and the developing animal brain is not a significant problem in children. Paediatr Anaesth 2015; 25: 65-72.
3. Zheng H, Dong Y, Xu Z, et al. Sevoflurane anesthesia in pregnant mice induces neurotoxicity in fetal and offspring mice. Anesthesiology 2013; 118: 516-26.

4. Vutskits L, Gascon E, Tassonyi E, Kiss JZ. Clinically relevant concentrations of propofol but not midazolam alter in vitro dendritic development of isolated gamma-aminobutyric acid-positive interneurons. Anesthesiology 2005; 102: 970-76.

5. Wang W, Zhang Z, Shang J, et al. Activation of group I metabotropic glutamate receptors induces long-term depression in the hippocampal CAl region of adult rats in vitro. Neurosci Res 2008; 62: 43-50.

6. Berns M, Zacharias R, Seeberg L, Schmidt M, Kerner T. Effects of sevofurrane on primary neuronal cultures of embryonic rats. Eur J Anaesthesiol 2009; 26: 597-602.

7. Pham X, Smith KR, Sheppard SJ, Bradshaw C, Lo E, Davidson $A J$. Implicit memory formation during routine anesthesia in children: a double-masked randomized controlled trial. Anesthesiology 2010; 112: 1097-104.

8. Yin J, Wang SL, Liu XB. The effects of general anaesthesia on memory in children: a comparison between propofol and sevoflurane. Anaesthesia 2014; 69: 118-23.

9. Taqhon TA, Masunqa AN, Small RH, Kashou NH. A comparison of functional magnetic resonance imaging findings in children with and without a history of early exposure to general anesthesia. Paediatric Anaesth 2015; 25: 239-46.

10. Wang C, Sadovova N, Fu X, et al. The role often methylas partate receptor in ketamine induced apoptosis in rat forebrain culture. Neuroscience 2005; 132: 967-77.

11. Backeljauw B, Holland SK, Altaye M, Loepke AW. Cognition and brain structure following early childhood surgery with anesthesia. Pediatrics 2015; 136: e1-12.

12. Kalkman CJ, Peelen L, Moons KG, et al. Behavior and development in children and age at the time of first anesthetic exposure. Anesthesiology 2009; 110: 805-12.

13. Wilder RT, Flick RP, Sprung J, et al. Early exposure to anesthesia and learning disabilities in a population-based birth cohort. Anesthesiology 2009; 110: 796-804. 